\title{
Evaluating Reading Material Formats on Children Learning in Science Education
}

\author{
Su-Ju Lu, Ying-Chieh Liu, Mei-Chun Lin, and Fang-Hsuan Lu
}

\begin{abstract}
Children nowadays are exposed with a variety of reading formats, however their influence on different types has not yet fully explored. This study examines learners' learning achievement and motivation involving in three different reading formats, i.e., text books, pop-up books, and AR e-books, in the context of natural science instruction focusing on household plants. Study participants of the 4th graders included six classes in northern Taiwan and were paired to form a control group of 43 students, an experimental group A with 52 students, and an experimental group B with 53 students. The results showed that students who learned with the AR e-book demonstrated significant improved learning achievement over those who used the printed textbook. As for learning motivation, no significant difference was found between the printed textbook and pop-up book groups, both were significantly better than that of the AR e-book group. This research contributed to the evaluation of the three reading formats that inherit various degrees in interactivity and digitization. The results could be useful when deciding an appropriate reading format under the consideration of reading comprehension and reading motivation. Further study include the improvement of learning motivation in the AR e-book.
\end{abstract}

Index Terms-Reading, augmented reality, pop-up book, reading material formats.

\section{INTRODUCTION}

Reading plays a key role in children's learning with reading comprehension and reading motivation serving as two major indicators. According to the International Association for the Evaluation for Educational Achievement (IEA), reading comprehension includes literary and informational comprehension as indications of children's capability of understanding texts in the context of daily life experiences. Reading motivation refers to children's willingness to read. Previous research [1] noted that children are not only expected to deconstruct and thus capture knowledge through reading, but are also expected to develop an intrinsic value in reading.

Reading is a basic means of acquiring information and knowledge [2] In children's education, instructors seek to strengthen learners' motivation through storytelling. Instructors engage learners and inspire them to develop

Manuscript received April, 15, 2018; revised August 22, 2018. This work was supported in part by the Ministry of Science and Technology, Taiwan (NSC-105-2221-E-182-044; 105-2511-S-152 -003 -MY2), and Research Fund of Chang Gung Memorial Hospital and Chang Gung University (BMRPD 67).

Su-Ju Lu, Mei-Chun Lin, and Fang-Hsuan Lu are with National Taipei University of Education, Taipei, 106, Taiwan (e-mail: lu@tea.ntue.edu.tw).

Ying-Chieh Liu is with the Department of Industrial Design, Chang Gung University, and Internal Medicine/Health Promotion Center, Chang Gung Memorial Hospital, Tao Yuan, Taiwan (email: ycl30@ mail.cgu.edu.tw). empathy, while motivating them to explore information and knowledge. Reading materials for children exist in a wide range of formats, but are often presented in terms of printed textbooks which consist mostly of text and pictures in varying ratios. Paper books are generally given preference due to their convenience, flexibility and portability [3]. Pop-up books [4], on the other hand, are print-based books which allow for the contents of stories to be displayed in a three dimensional space. This type of format increases interaction while providing an increased sense of realism. With recent advances in information technology, children today also frequently read on screen-based or portable e-book devices-based. Another technology, Augmented Reality (AR), has emerged to integrate simulated visualizations into authentic backgrounds, providing a means of timely and ubiquitous interaction to present supplementary information in specific contexts [5].

To examine the influence of reading material format on learning, Tare, Chiong, Ganea, and Deloache [6] compared the impact of images, picture books and pop-up books on children's learning, and found that pop-up books result in high motivation, but not necessarily in improved knowledge acquisition. Korat [7] found that using e-books for reading stories resulted in improved understanding of word meanings and story content as compared to traditional books. Huang, Liang, Su, and Chen [8] designed an Interactive E-book Learning System (IELS) for use by elementary school students, and found no improvement in learning achievement over traditional books. However, the children indicated a high level of interest in IELS format. The aforementioned studies do not mention the use of enhanced formats in interaction using traditional (e.g., pop-up books) or technological formats (e.g., AR e-books), thus further investigation is needed on the impact of different reading material formats on learning.

Interactivity is the process of exchange, response, and feedback between human beings and objects [9] Previous studies have mainly focused on providing comparisons between textbooks and pop-up books, or between textbooks and e-books. However, few studies have attempted to compare all three formats that have different levels of interactivity and digitization. Given the range of views and findings regarding the introduction of digital technologies into reading materials, there is still considerable space for discussion in this regard.

This study examined the effect of reading material format in terms of learning motivation and achievement. Children was examined in the context of natural science instruction focusing on household plants. A group using conventional textbooks is treated as a control group, while experimental group A used a pop-up book and experimental group B uses an AR e-book. These three groups were then compared to 
identify potential effects of reading material format on learning achievement and motivation.

\section{RELATED RESEARCH}

\section{A. Pop-up Books}

Before the popularization of digital technologies, pop-up books were a popular medium for increasing realism and interaction in reading, with each page presenting a display of $3 \mathrm{D}$ objects to attract the attention of readers and to stimulate their thinking [10]. For children, pop-up books are like toys in that they provide visual, tactile and potentially auditory stimulation during reading. Reading a pop-up book provides a mechanism for the transfer of knowledge while stimulating intellectual potential. Studies have shown that children find $3 \mathrm{D}$ representations more stimulating than conventional printed books, but not in improving knowledge acquisition [6].

\section{B. Digital Reading}

The development of information technologies has revolutionized the dissemination of knowledge. Digital technologies are rapidly being integrated into games and learning materials. Readers can directly access digitized books online, along with related video, text streams and hyperlinks [11]. Reading through interactive multimedia has changed the way people learn, and the flexibility provided by multimedia technologies helps students learn with ease. Nelson et al. [12] suggested that changes in the use of information technology have impacted instructional and learning methods in such a way that a digital-based curriculum is better able to attract student interest in learning [12].

E-books are widely seen as having pros and cons for learning. Some learners are reluctant to recommend others purchase e-book products, while others are generally willing to use them as a replacement for paper-based books [13]. Some studies have found that learning outcomes using e-books are inferior to those using traditional textbooks [14]-[16]. In addition, some scholars believe that student use of e-books is associated with higher levels of affective and psychomotor learning [17], and thus has a positive impact on learning. However, the specific characteristics of digital media have an impact on learning outcomes, and e-books should be designed according to how they are used in practice, rather than simply trying to emulate the usage experience of printed books [18]. Bierman, Ortega, and Rupp-Serrano [19] indicated that users expressed the desire to interact with instructional resources through e-books, and such interaction seems to be a mandatory feature in e-book design. Based on the potential of e-books, previous studies have suggested that e-book mechanisms must be improved to increase the feasibility of using them in learning applications, and that the suitability of such devices for used in learning must be carefully assessed [13], [18].

\section{AR e-Books}

Previous studies have found positive with the use of AR in educations in enhancing learning effect [20]-[22].
AR e-book has the distinctive feature of inserting virtual objects into authentic contexts [5]. AR creates a feeling of immersion which provides students with additional learning opportunities in an integrated learning environment. AR e-book, in this study, was to utilize specific markers paired with specific concepts and their corresponding learning content. The user could focus the tablet computer's camera on the label sensors to trigger supplemental content. Chen and Chao [23] integrated concepts for reading instruction with Marker-based AR to promote learner knowledge acquisition by printing images or icons in the book; the user can activate these images to access supplementary information. Ozcelik and Acarturk [24] suggested Marker-based AR can be used as a supplement to textbooks to promote learning, and users were found to agree that Marker-based AR is an effective way of providing access to supplementary reading materials [25].

\section{METHOD}

\section{A. Objectives}

This study was motivated to examine the impact of three types of reading material on learning outcomes among children. The research questions are as follows:

1) Do the three types of reading material have different impacts on the learning achievement of children?

2) Do the three types of reading material have different impacts on the learning motivation of children?

\section{B. Material}

To investigate the three research questions, learning materials were developed based on the three formats. The learning materials were designed for 3 rd and 4th grade elementary school students. The content is derived from "The Management of Indoor Air Purification Plants (Home Edition)" published by the Executive Yuan's Environmental Protection Administration [26], along with excerpts from interviews conducted with three domain experts. Two common house plants (Hypoestes sanguinolenta and syngonium) were selected for their air purification performance. The characteristics plants are introduced in four sections: Basic introduction to plants (origins, names, etc), plant appearance characteristics (leaf shape, color), cultivation methods (soil, humidity) and environmental sustainability functions (carbon dioxide reduction, transpiration, etc).

\section{Story Picture Book}

A story book was developed with playful and imaginatively-designed characters and scenes. The story content took place on a planet where the air is very dirty because of a lack of plants. The main character found a way to deal with the pollution and save the planet. The story was is used as a driver for pursuing the learning goals and attracting learner interest. Markers (used for AR e-books) were located within in the corners of the book pages to provide suggestions for supplementary learning content, as shown in Fig. 1.

\section{Textbook}

Content taken from p. 118-119 and 150-151 of "The Management of Indoor Air Purification Plants (Home 
Edition)" [26] was adapted as the subject matter of the learning content book. As shown in Fig. 4, the learning material for the control group contained (counter-clockwise starting from the top left) images of plants, environmental sustainability function charts, a basic text-based description of plants (including their origins and names), plant characteristics (including leaf shape and color), and cultivation methods (soil and humidity conditions).

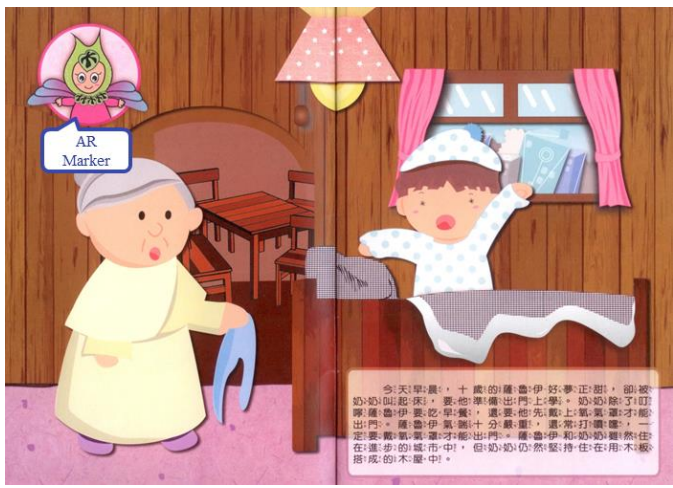

Fig. 1. Story picture book.

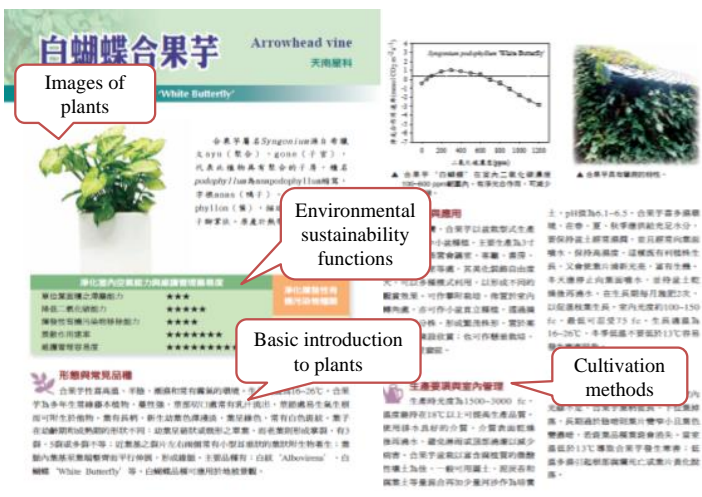

Fig. 2. Textbook.

\section{E. Pop-up Books}

Pop-up books were constructed such that elements of the page can spring out to create a three-dimensional image. A pop-up book was designed based on the instructional content, integrating the four aspects of plant knowledge into a pop-up book featuring 3D renderings of plants. Both the pop-up book and the AR e-book featured Chinese phonetic support to help students sound out unknown characters. Fig. 3 showed the same content displayed in the textbook, pop-up book and e-book. The pop-up book differed from the textbook in that pop-up book provided three-dimensional plant illustrations. When the learner was reading the supplemental content, these labels could be affixed to the corresponding image to create a cognitive link to the learning content. Fig. 2 showed supplementary pages designed to ensure that the content of the pop-up book and is consistent with that of the textbook. Once the teaching materials were developed, they were reviewed by experts.

\section{F. AR e-Book}

The design of the AR e-book is similar to that of the pop-up book in that it provides phonetic support to help learners identify unknown characters. As shown in Fig. 4, by aiming the built-in camera on the labels within the story book, students interact with virtual objects within the e-book interface. The buttons on the right provide access to the knowledge structure, with each button representing one of the four knowledge themes. Clicking a button leads the learner to learning content related to a particular aspect of the plants, while directional arrows on the bottom allow users to turn the page. The teaching materials are presented on the left. The contents of the textbook, pop-up book and AR e-book are identical, and differ only in terms of presentation.

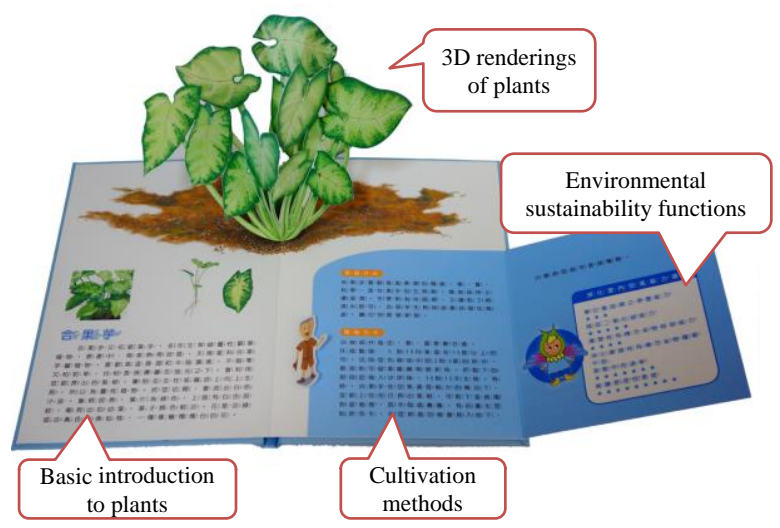

Fig. 3. Pop-up book design.

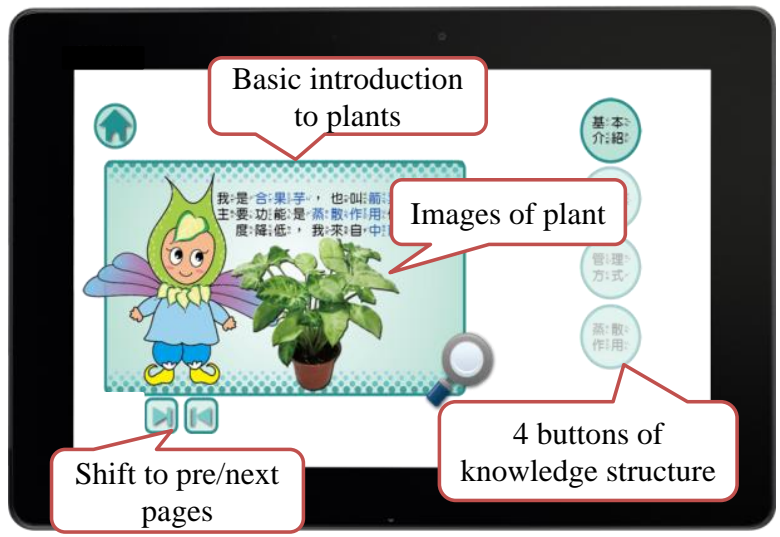

Fig. 4. Pop-up book design.

The system uses D'fusion for development design. D'fusion is an AR development environment for mobile devices characterized by sensor sensitivity and speed. The use of sensing technology allows the camera built into the mobile device to recognize sensors embedded in the labels to trigger digital content. After sensing is completed, the mobile device reads from the database to present illustrations and learning materials on the screen.

\section{EXPERIMENT DESIGN}

To evaluate the impact each type of reading material format had on learner reading habits, the study conducted experiments using the "Green Plants" unit from an elementary school natural science course. Three types of outcomes were assessed, i.e., student learning achievement and learning motivation.

\section{A. Participants}

Study participants included six fourth grade classes from two elementary schools in northern Taiwan. Classes were randomly paired to form a control group of 43 students, an experimental group A with 52 students, and an experimental 
group B with 53 students. The total participant group included 148 students, including 76 boys and 72 girls (see Table I).

\section{B. Research Tools}

The research was conducted using a quasi-experimental study, including a pre-test, a post-test, a pre-activity questionnaire, and a post-activity questionnaire to measure student learning achievement and motivation. The questions were designed to ensure the learners understand the aspects of plant appearance, environmental sustainability functions, and cultivation methods. The pre-test was designed to evaluate the students' prior knowledge through 10 yes-or-no items and 10 multiple-choice items. The post-test used 5 multiple-choice items, 5 matching items and 10 fill-in-the-blank items to assess student knowledge of the two plants after reading the learning materials.

The learning motivation questionnaire was modified from the Motivated Strategies for Learning Questionnaire (MSLQ) developed by Pintrich and Groot [27]. The original questionnaire examined five dimensions including self-efficacy, intrinsic value, test anxiety, cognitive strategy use and self-regulation. Self-efficacy refers to an individual's ability to judge his or her own ability to perform actions to achieve a specific goal [28], while intrinsic value is a subjective assessment of the value of the learning process, focusing on the process rather than the outcome [29]. This study aims to explore the impact of various reading material formats on children's learning. Motivation and self-efficacy are considered to be related factors for reading. The three other dimensions of test anxiety, cognitive strategy use and self-regulation are not included in this study, thus we sampled self-efficacy and intrinsic value as the determining criteria for this study. The questionnaire consisted of 18 items (e.g., "This class can help me learn new things and is challenging" and "The content of this activity will help me learn about how to beautify my home"). A 5-point Likert scale was used instead from 1 (strongly disagree) to 5 (strongly agree). Average responses were calculated to provide a motivation score, with a higher average indicating a higher degree of motivation. The Cronbach's alpha value of the questionnaire was 0.94 , while those of the two dimensions are 0.91 and 0.89 , respectively.

\section{Experiment Procedures}

Prior to the learning activity, all students went through two weeks of instruction in basic knowledge of plants, which was part of the elementary school natural science curriculum. At the beginning of the learning activity, the students took the pre-test and the pre-questionnaire. During the learning activity, the three groups went through guided learning activities, with students in the control group using the printed textbook, experimental group A using the pop-up book, and experimental group B using the AR e-book. The learning content was designed to be consistent for all three groups. The three types of books were reviewed by three experts to ensure content consistency. Each group broke into teams of 4-5 students for the learning activities. Due to resource limitations, each team in experimental groups A and B was provided with one copy of the pop-up book and the AR e-book, respectively, while each member of the control group has his/her own copy of the textbook.

After the learning activity, the students took the post-test and the post-questionnaire to measure learning achievement and learning motivation.

\section{Analysis}

We used the ANOVA test for the three-group comparison. Also, we also use MANCOVA to test differences among the three groups using the pretest as the covariate and the post-test as dependent variables.

\section{RESUltS}

\section{A. Learning Achievement}

The ANOVA result $(F=10.15, p<.05)$ showed that the results differed significantly among the three groups and, as shown in Table I, the three groups did not have equivalent knowledge prior to the activity. This can be explained by the fact that the students were recruited from two schools and were taught by different teachers.

As shown in Table II-, the MANCOVA results $(F=4.70, p$ $<.05)$ showed a significant difference among the three groups. However, no significant difference was found between the AR e-book and pop-up book groups in terms of learning achievement; likewise there was no significant difference between the pop-up book and printed textbook. However, students who learned with the AR e-book demonstrated significant improved learning achievement over those who used the printed textbook.

\section{B. Learning Motivation}

As shown in Table III, the results $(F=6.04, p<.01)$ indicated significant differences among the three groups. No significant difference was found between the printed textbook and pop-up book groups in terms of learning motivation, but the AR e-book group showed significantly lower learning motivation than the other two groups.

TABLE I: ANOVA RESULT OF THE PRE-TEST SCORES FOR LEARNING ACHIEVEMENT

\begin{tabular}{|c|c|c|c|c|c|}
\hline Groups & $\mathrm{N}$ & Mean & S.D. & $\mathrm{F}$ & \\
\hline (a) Control & 43 & 25.34 & 12.37 & $10.15^{* * *}$ & (b) $>$ (a) \\
\hline (b) Experimental A & 52 & 38.61 & 15.82 & & $(c)>(a)$ \\
\hline (c) Experimental B & 53 & 34.98 & 15.03 & & \\
\hline
\end{tabular}

${ }^{*} p<.05, \stackrel{* *}{p<.01,}, \stackrel{* * *}{p<}<.001$ 
TABLE II: MANCOVA OF THE POST-TEST RESULTS FOR LEARNING ACHIEVEMENT

\begin{tabular}{|c|c|c|c|c|c|c|c|}
\hline Groups & $\mathrm{N}$ & Mean & S.D. & Adjusted mean & Std. error & $F$ & \\
\hline (a) Control & 43 & 42.02 & 10.85 & 41.89 & 2.07 & \multirow[t]{3}{*}{$4.70^{*}$} & (c) $>$ (a) \\
\hline (b) Experimental A & 52 & 45.28 & 13.49 & 45.37 & 1.84 & & \\
\hline (c) Experimental B & 53 & 50.13 & 13.93 & 50.15 & 1.78 & & \\
\hline
\end{tabular}

TABLE III: MANCOVA OF MOTIVATION VALUE POST-TEST RESUlTS

\begin{tabular}{|c|c|c|c|c|c|c|c|}
\hline Groups & $\mathrm{N}$ & Mean & S.D. & Adjusted mean & Std. error & $F$ & \\
\hline (a) Control & 43 & 3.89 & 0.75 & 3.91 & 0.08 & \multirow[t]{3}{*}{$6.04 * *$} & (a) $>$ (c) \\
\hline (b) Experimental A & 52 & 4.10 & 0.56 & 3.91 & 0.08 & & \multirow[t]{2}{*}{ (b) $>$ (c) } \\
\hline (c) Experimental B & 53 & 3.39 & 0.96 & 3.55 & 0.08 & & \\
\hline
\end{tabular}

\section{DISCUSSION}

This study investigated the impact of various types of reading material formats. Three formats were built based on the same narrative, allowing for comparison of impact on learning achievement and motivation. A printed textbook was used for the control group, while the two experimental groups used a pop-up book and an AR book. The following discussions were made based on analysis of paired pretest and post-test during the learning activity and a pre and post questionnaire.

This study's integration of AR mechanisms in e-books represented a new direction in the study of learning achievement. No significant difference was found between the AR e-book and the pop-up book in terms of learning achievement. Students using the AR e-book showed improved learning achievement over students who used the textbook. Our findings differed from results reported by Kang et al. [12], Daniel and Woody [30], and Huang et al. [8], possibly because traditional e-book formats presented digitized content in a fixed, two dimensional rendering, without reference to the characteristics of the instructional content or the user's experience. The AR e-book was designed to provide learners with a timely convergence of the learning material during learning activities. The AR e-book presented in this research differs from conventional e-books in that it not only includes functions triggered by markers, but that the content was is designed according to the usage experience of the child learners, thus departing from traditional fixed, two-dimensional presentations.

In terms of learning motivation, results from using the AR e-book were inferior to those using the non-digital pop-up book and the printed textbook. These results differ from previous findings, e.g., Rockinson- Szapkiw et al. [17] suggested that the use of e-books produced increased emotional learning as compared to printed textbooks, along with higher levels of affective and psychomotor learning. One potential reason for this discrepancy was that our study worked with elementary school students with a high familiarity with technology, thus the use of technology did not contribute to increased interest or engagement. However, this needed to be confirmed by further investigation.

\section{A. Potential Limitation}

Given time and resource constraints, the content of this study was limited to learning material related to the two household plants. While there are many types of pop-up books and AR implementations, this study discussed discusses the application of specific types of pop-up books and AR e-books. The research subjects were are urban children who have extensive experience in using multimedia applications, thus the results could not cannot necessarily be extended to rural children or those with limited experience with digital technologies.

A potential confound with the study came from resource limitation. Unlike students in the print textbook, students in both experimental conditions worked in groups. Working in groups may experience many social effects as well as grade inflation that could affect their scores compared to students in the print textbook group who read as individuals. Further, the study added Chinese phonetic support to the two experimental groups but not the control group.

\section{CONCLUSION}

The development technology has produced changes in reading formats and experiences. This study examined the impact of a range of reading material formats, specifically printed textbooks, pop-up books and AR e-books in the context of elementary school instruction on household plants. This research contributed to the evaluation of the three reading formats for the target group. The results could be useful for deciding an appropriate reading format when considering the factors in reading comprehension and reading motivation.

\section{ACKNOWLEDGMENT}

The authors would like to thank students, teachers and research assistants who were participating of this research. We gratefully appreciate the Ministry of Science and Technology, Taiwan under Contract No. MOST105-2221-E-182-044; 105-2511-S-152 -003 -MY2, and the Research Fund of Chang Gung Memorial Hospital and Chang Gung University (BMRPD67).

\section{REFERENCES}

[1] I. V. Mullis et al., PIRLS 2006 International Report, Boston: IEA, 2006.

[2] J. Gere, B.-A. Kozlovich, and D. A. Kelin, By Word of Mouth: A Storytelling Guide for the Classroom, ERIC Clearinghouse, 2002.

[3] M. R. Morris, A. J. B. Brush, and B. R. Meyers, Reading Revisited: Evaluating the Usability of Digital Display Surfaces for Active Reading Tasks, 2007. 
[4] D. Birmingham, "Pop-up design and paper mechanics: how to make folding paper sculpture," Guild of Master Craftsman, 2011.

[5] R. T. Azuma, "A survey of augmented reality," Teleoperators and Virtual Environments, vol. 6, pp. 355-385, 1997.

[6] M. Tare et al., "Less is more: How manipulative features affect children's learning from picture books," J Appl Dev Psychol, vol. 31, no. 5 , pp. 395-400, 2010.

[7] O. Korat, "Reading electronic books as a support for vocabulary, story comprehension and word reading in kindergarten and first grade," Computers \& Education, vol. 55, no. 1, pp. 24-31, 2010.

[8] Y.-M. Huang et al., "Empowering personalized learning with an interactive e-book learning system for elementary school students," Educational Technology Research and Development, vol. 60, no. 4, pp. pp. 703-722, 2012.

[9] R. V. Price, Computer-Aided Instruction: A Guide for Authors Belmont, CA: Wadsworth, 1991.

[10] T. Jacobs. (2010). Children's pop-up books flop as learning tool. [Online]. Available: http://www.psmag.com/education/childrens-pop-up-books-flop-as-lea rning-tool-20691/

[11] W. D. Chesser, "Chapter 5: The e-textbook revolution," Library Technology Reports, vol. 47, no. 8, pp. 28-40, 2011.

[12] L. L. Nelson et al., "Trading textbooks for technology: New opportunities for learning," Phi Delta Kappan, vol. 92, no. 7, pp. 46-50, 2011.

[13] J. A. Shepperd et al., "Evaluating the electronic textbook: Is it time to dispense with the paper text?" Teaching of Psychology, vol. 35, no. 1, pp. 2-5, 2008.

[14] Y.-Y. Kang et al., "Usability evaluation of e-books," Displays, vol. 30, no. 2 , pp. 49-52, 2009.

[15] J. Noyes and K. Garland, "Student's attitudes towards books and computers," Computers in Human Behavior, vol. 21, pp. 233-241, 2005.

[16] J. Noyes and K. Garland, "Explaining student's attitudes toward books and computers," Computers in Human Behavior, vol. 22, pp. 351-363, 2006.

[17] A. J. Rockinson-Szapkiw et al., "Electronic versus traditional print textbooks: A comparison study on the influence of university students' learning," Computers \& Education, vol. 63, pp. 259-266, 2013.

[18] W. D. Woody et al., "E-books or textbooks: Students prefer textbooks," Computers \& Education, vol. 55, no. 3, pp. 945-948, 2010.

[19] J. Bierman et al., "E-book usage in pure and applied sciences," Science \& Technology Libraries, vol. 29, no. 1-2, pp. 69-91, 2010.

[20] S. Cai et al., "Applications of augmented reality-based natural interactive learning in magnetic field instruction," Interactive Learning Environments, vol. 25, no. 6, pp. 778-791, 2017.

[21] S. J. Lu and Y. C. Liu, "Integrating augmented reality technology to enhance children's learning in marine education," Environmental Education Research, vol. 21, no. 4, pp. 525-541, 2015.
[22] S. J. Lu et al., "Design and evaluation of AR enabled wall stickers with interactivity and digital contents for children learning," The International Journal of Early Childhood Learning, vol. 19, no. 2, pp. 43-48, 2013

[23] G.-D. Chen and P.-Y. Chao, "Augmenting traditional books with context-aware learning supports from online learning communities," Educational Technology \& Society, vol. 11, no. 2, pp. 27-40, 2008.

[24] E. Ozcelik and C. Acarturk, "Reducing the spatial distance between printed and online information sources by means of mobile technology enhances learning: using 2D barcodes," Computers \& Education, vol. 57, no. 3, pp. 2077-2085, 2011.

[25] N.-S. Chen et al., "Augmenting paper-based reading activity with direct access to digital materials and scaffolded questioning," Computers \& Education, vol. 57, no. 2, pp. 1705-1715, 2011.

[26] T.-M. Yeh, The Management of Indoor Air Purification Plants (Home Edition), Taiwan: Environmental Protection Administration Executive Yuan, 2010

[27] P. R. Pintrich and E. V. D. Groot, "Motivational and self-regulated learning components of classroom academic performance," Journal of Educational Psychology, vol. 82, no. 1, pp. 33-40, 1990.

[28] A. Bandura, "Self-efficacy: Toward a unifying theory of behavioral change," Psychological Review, vol. 84, no. 2, pp. 191-215, 1977.

[29] A. Wigfield and J. S. Eccles, "Expectancy-value theory of achievement motivation," Contemporary Educational Psychology, vol. 25, pp. 68-81, 2000.

[30] D. B. Daniel and W. D. Woody, "E-textbooks at what cost? Performance and use of electronic v. print texts," Computers \& Education, vol. 62, pp. 18-23, 2013.

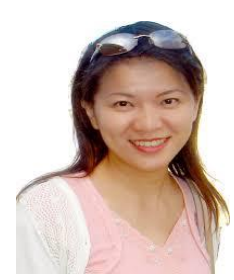

Su-Ju Lu is a faculty member in the Department of Digital Technology Design at National Taipei University of Education, Taiwan. Her research interests include e-learning, toy/game-based learning, augmented reality, and digital education product for children.

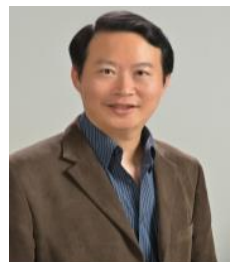

Ying-Chieh Liu serves as associate professor in industrial design department at Chang-Gung University. His research interests focus on engineering design and interdisciplinary design to improve design/innovation effectiveness. specific interests include conceptual design, mhealth, inclusive design, and interdisciplinary design. 